\title{
EFEITO DA DENSIDADE DE POPULAÇAOO DE PLANTAS SOBRE A CULTURA DO REPOLHO \\ (Brassica oleracea var. capitata L.) *
}

\author{
KEIGO MINAMI ** \\ RICARDO VICTORIA FILHO **
}

RESUMO

Com a finalidade de avaliar o efeito da densidade de população de plantas sobre a cultura de repolho (Brassica oleracea var. capitata L.), foi realizado um expe rimento no Campo Experimental do Setor dé Horticultura da Escola Superior de Agricultura "Luiz de Queiroz", Piracicaba, São Paulo, em um Latossol Roxo, Série Luiz de Queiroz, utilizando-se os espaçamentos de $0,60 \mathrm{~m} \times 0,80 \mathrm{~m} ; 0,60 \mathrm{~m} \times$ $0,65 \mathrm{~m} ; 0,60 \mathrm{~m} \times 0,4.5 \mathrm{~m} ; 0,60 \mathrm{~m} \times 0,30 \mathrm{~m}$ e $0,60 \mathrm{~m} \times 0,15 \mathrm{~m}$.

A medida em que se aumentou a densidade de população, houve as seguintes alterações na planta de repolho: mu lançade for mato chato da "cabeça" para cônico, redū

* Entregue para publicação em 03/11/1980.

** Departamento de Agricultura e Horticultura, E.S.A. "Luiz de Queiroz, USP. 
ção do número de folhas, tamanho (peso, volume e diâmetros transversal e longitudinal), aumento na densidade da "cabeça" (peso/volume) e aumento na porcentagem de plantas que não produziram "cabeça".

\section{INTRODUÇÃO}

As hortaliças podem ser afetadas na sua produção pela densidade de população. Em geral, a produção tende a aumentar com o aumento da densidade, como o verificado nas culturas da alface (SALE, 1966 e NELDER \& MOSS, 1956), beterraba (ROBINSON \& WORKER JR., 1969), cenoura (MINAMI \& DEMETRIO, 1978) e rabanete (LUCCHESI et alii, 1976).

Por outro lado, a densidade provoca também mudanças na qualidade do produto. Por exemplo, o peso do fruto de tomate diminui com o aumento da densidade (VITTUM \& TAPLEY, 1953, 1957), o peso da espiga do milho doce diminui com o aumento da população (GENTER \& CAMPER JR., 1973), o mesmo acontecendo com a cabeça do brócolo (ZINK \& AKANA, 1951), raiz de beterraba (MACK, 1979), etc.

Neste trabalho, foram estudados os aspectos da produção da cultura do repolho em relação à densidade.

MATERIAL E METODOS

O experimento foi conduzido no Campo Experimental do Se tor de Horticultura da Escola Superior de Agricultura "Luiz̄ de Queiroz", Piracicaba, São Paulo, de abril a julho de 1977.

o solo é um latossol roxo, série Luiz de Queiroz, de pH em torno de 6,0, com alto teor de C, alto em fósforo, potássio, cálcio e magnésio, e zero de aluminio.

o clima da região, segundo a classificação de Kłppen, é Cwa - tropical úmido com inverno seco, temperatura do més mais quente superior a 22,5 :C. 
A ärea do experimento foi tratada com o herbicida trifluralin a $1,2 \mathrm{~kg}$ do i.a. por hectare, vinte dias antes do transplante, e incorporado com enxada rotativa logo após a aplicação. O controle posterior das plantas daninhas foi executado manualmente.

Para uniformização, a área foi adubada na base de 50 $\mathrm{g} / \mathrm{m}^{2}$ do adubo 4-16-8. Aos 20 e 40 dias após o transplante, fo ram colocadas $10 \mathrm{~g}$ de sulfato de amônia por planta e por vez.

0 cultivar utilizado foi 'Ban-chu', de formato chato, coloração verde escuro, ciclo médio, pesando de $2,0-2,5 \mathrm{~kg}$, tolerante a Xanthomonas. As sementes foram obtidas da firma Agroflora S.A. e apresentavam 95\% de germinação, tendo sido tratadas com Arasan (Thiran).

Para obtenção de mudas, foram feitas semeaduras em linha e o canteiro coberto com folhas de palmeira. Após vinte dias, a cobertura já tinha sido totalmente retirada. Durante esta fase foram feitas duas aplicações de Endrex (Endrin) a $25 \mathrm{ml}$ do produto comercial por 101 de água para controlar a vaquinha (Epicauta atomaria). Aos 25 dias, as mudas foram re gadas com uma solução de $30 \mathrm{~g}$ de sulfato de amônia em $101 \mathrm{de}$ água e logo em seguida novamente regadas com água somente pa ra evitar queimaduras.

As mudas foram transplantadas com 32 dias, quando estavam no estädiode 5 a 6 folhas definitivas. Logo após o transplante foi feita uma irrigação no sulco. Esta operação, sempre em sulco, repetiu-se a cada 4-5 dias até o final do experimento.

Aos 20 dias após o transplante, fez-se o achegamento da terra às plantas.

Durante o transcorrer do experimento foram feitas pulverizações à base de dithane e com inseticidas fosforados. Pulverizou-se duas vezes solução de bórax a $0,5 \%$, aos 40 e 60 dias.

o replantio das mudas que falharam foi feito cincodias 
após o transplante. Durante a condução do experimento, não se constatou mais nenhuma falha.

O delineamento usado foi o de NELDER (1962), denominado delineamento sistemático. Fez-se uma modificação, conforme MINAMI (1977), onde o raio das circunferências foi aumentado em valor constante de $0,6 \mathrm{~m}$, com 4 repetições.

Os tratamentos considerados foram:

$$
\begin{aligned}
& A-0,60 \mathrm{~m} \times 0,80 \mathrm{~m} \\
& B-0,60 \mathrm{~m} \times 0,65 \mathrm{~m} \\
& C-0,60 \mathrm{~m} \times 0,45 \mathrm{~m} \\
& D-0,60 \mathrm{~m} \times 0,30 \mathrm{~m} \\
& \mathrm{E}-0,60 \mathrm{~m} \times 0,15 \mathrm{~m}
\end{aligned}
$$

Cada parcela constou de 6 plantas üteis e foram observados os seguintes parâmetros:

a) peso da cabeça, sem as folhas externas;

b) volume em $\mathrm{cm}^{3}$, determinado através do deslocamento da água em uma cuba, pela imersão completa da "cabeça" (PEARSON, 1931, modificado);

c) diâmetro transversal e longitudinal;

d) número de folhas externas;

e) densidade peso/volume

A anālise estatistica foi feita conforme GOMES (1970). Os dados expressos em porcentagem foram transformados em $\mathrm{Y}=\operatorname{arc} \operatorname{sen} \sqrt{\mathrm{x}}$, de acordo com SNEDCOR E COCHRAN (1967), para maior aproximação da distribuição normal e obter maior sen sibilidade das variações entre os tratamentos. Na determinação dos contrastes entre as médias, utilizou-se o Teste de Tukey. 


\section{RESULTADOS E DISCUSSÃO}

As médias das 4 repetições para peso de "cabeça", diâmetro longitudinal e transversal, volume, númerode folhas, densidade e plantas que não formaram cabeça, encontram-se na Tabela 1.

Embora haja um aumento no número de plantas à medida que se aumenta a densidade de população, não há uma correspondência em produção porque, além de haver redução no tamanho das "cabeças", há um aumento na porcentagem de plantas que não formam "cabeça" com o aumento da população. O aumento na quantidade de plantas de repolho sem "cabeça" nos plan tios mais densos também foi obtido por DREW (1966), especial mente nos tratamentos sem irrigação.

HODNETT \& CAMPBELL (1963) não obtiveram aumento na produção por hectare em espaçamentos menores que $46 \mathrm{~cm}$ por $46 \mathrm{~cm}$, atribuindo a causa ao aumento no número de plantas que falha ram em formar cabeça e redução no peso da "cabeça", em densi dades maiores.

A planta de repolho vai se tornando menor à medida que a densidade de população aumenta, através da redução do núme ro de folhas, no volume e peso da "cabeça", na densidade $\bar{e}$ no tamanho, conforme pode ser visto na Tabela 1. Além disso, há uma tendência do formato da "cabeça" a se mudar (relação diâa metro longitudinal/transversal vai aumentando). 0 híbridō 'Ban-chu', normalmente de formato chato, tende a alongar-se com o aumento da pressão de competição. ARAUJo (1975) obteve resultados semelhantes, mesmo usando cultivares de verão. A redução no tamanho do repolho em densidades el Łvadas também foi obtida por HODNETT \& CAMPBELL (1963), DREW (1966) e ARRA TANAKUL, BAGGETT \& MACK (1977).

O repolho possui duas fases bastante distintas em rela ção ao seu crescimento vegetativo (NORTH, 1957): a primeira, de crescimento lento e a segunda, de crescimento muito rápido, chegando a dobrar de peso a cada nove dias. Se a primeira fase so frer qualquer interferência (seja por falta de àgua, ataque de iñ setos, e até mexmo por competição entre as duas plantas vizinhas ou plantas daninhas), a segunda fase $\bar{e}$ automaticamente afeta da (NORTH, 1957; DREW, 1966). 


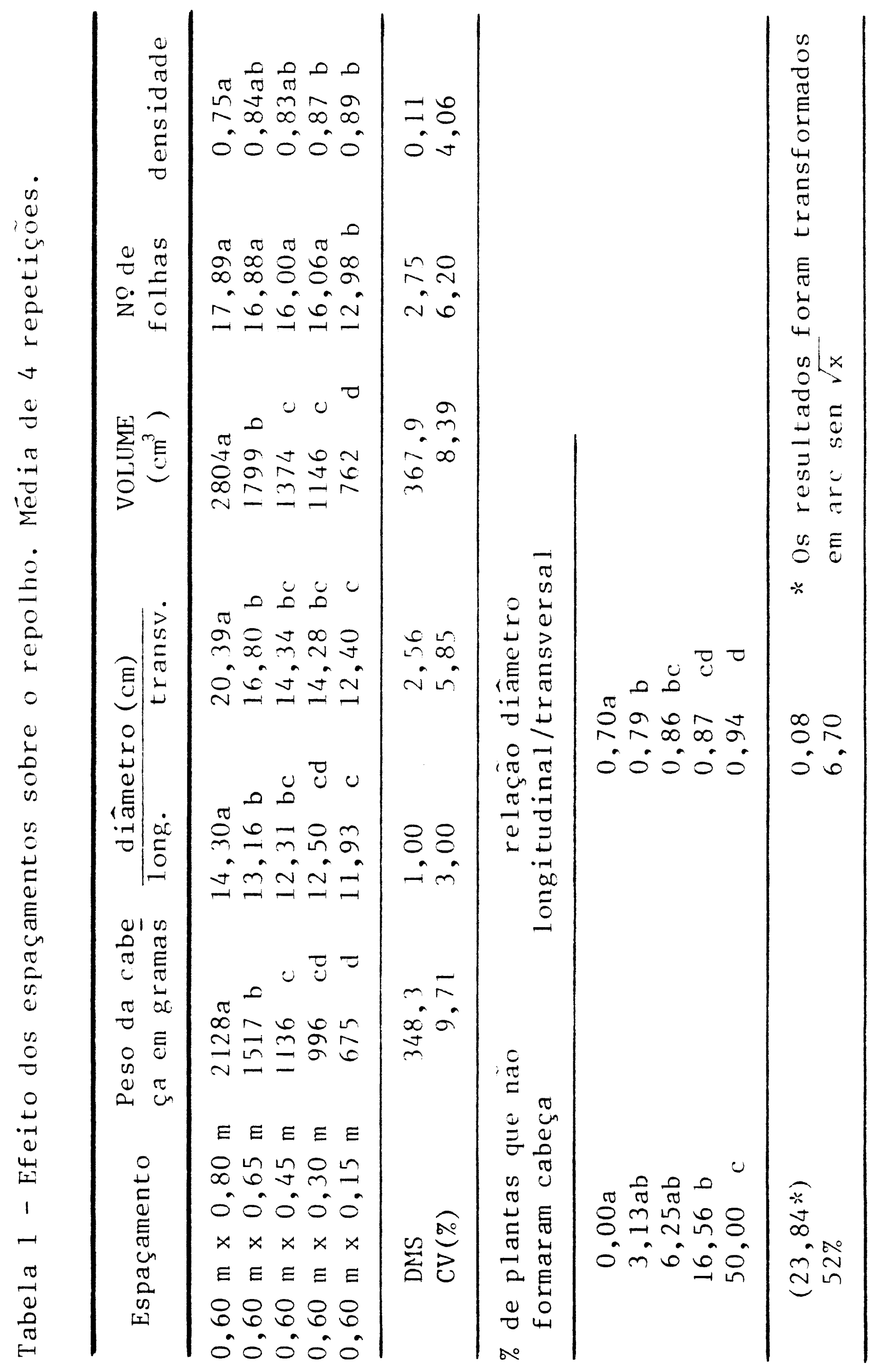


Para KNOTT (1951), a redução no tamanho do repolho se deve à redução na ārea foliar, influindo, portanto, negativa mente na atividade fotossintética. A diminuição da área foliar, por sua vez, é resultante do menor desenvolvimento das folhas, principalmente do número de folhas, resultante da com petição.

Contudo, MOSS \& STINSON (1961), AIESERL, RIVENBARK \& HAGEMAN (1963), YAO \& SHAW (1964 a e b), WILLIAMS, LOOMIS \& LEPLEY (1965) e MINAMI (1977) apoiam a teoria segundo a qual - aumento no sombreamento entre as plantas vizinhas leva à redução no tamanho das plantas em espaçamentos menores. Segundo ZIESERL, RIVENBARK \& HAGEMAN (1963), períodos curtos de sombreamento podem reduzir drasticamente o nivel de redūtase de nitrato na planta, e, consequentemente, afetar o aproveitamento do nitrogênio e o crescimento da planta.

\section{CONCLUSÃO}

Para as condições do experimento pode-se concluir que:

1. a influência da competição é muito grande sobre o repolho;

2. ofeito da densidade de população sobre a cultura do repolho pode ser observado na mudança do formato da "cabeça", redução do número de folhas, do tamanho (peso, volume e diâmetro transversal e longitudinal), aumento na densidade e na porcentagem de plantas que não se formam "cabeça".

\section{SUMMARY}

EFFECTS OF PLANT POPULATION DENSITY ON CABBAGE

(Brassica oleracea var. capitata L.) CROP

In order to study the effects of plant population density on cabbage crop (Brassica oleracea var. capitata), an experiment using different spacing $(0,60 \mathrm{mx} 0.80 \mathrm{~m}, 0.60 \mathrm{~m} \quad \mathrm{x}$ 
$0.65 \mathrm{~m}, 0.60 \mathrm{~m} \times 0.45 \mathrm{~m}, 0.60 \mathrm{~m} \times 0.30 \mathrm{~m}$, and $0.60 \mathrm{~m} \times 0.15 \mathrm{~m})$ was carried out.

There were the following changes in cabbage plants due to increasing population density: plant head became conical: number and size (weight, volume and diameters) of leaves decreased; density (weight/volume) and percentage of plants forming no head increased.

\section{LITERATURA CITADA}

AKRATANAKLI, W., BASSET, J.R.; MACK, H.J., 1977. Effecrs of plant spacing, fertilizer, and transplanting on axillary heading in cabbage, Eraze $2 a$ apor L. (capitata group). Hort. Science 12: 56-57.

ARAEJO, L.C.P., 1975. Efeitos de população de plantas em cultivares de repolho de verão (Enasica ciepaca var. vaizá.: L.). Dissertação para obtenção do título de Mestre, ESALQ, Piracicaba, 79p.

DREW, D.H., 1966. Irrigation studies on summer cabbage. Jour. Hort. Sci. 41:103-114.

GENTER, C.F.; CAMPER JR., H.M., 1973. Component plant part development in maize as affeceted by hybrids and population density. Agron. Journ. 65: 669-671.

GOMES, F.P., 1970. Curso de Estatística Experimental, 4 a ed., Piracicaba, 430p.

HODNETT, G.E.; CAMPBELL, J.S., 1963. Effect of spacing on yield on cabbage and lettuce in Trinidad. Tropical Horticulture 40: 103-108.

KNOTT, J.E., 1951. Palestras sobre horticultura, Reitoria da USP, mimeografado, 231p.

LUCCHESI, A.A.; MINAMI, K.; KALIL FO, A.N.; KIRYU, J.N.; JUNIOR, J.P., 1976. Produtividade do rabanete (Raphanus zativus L.) relacionado com a densidade de população. An. Esc. Sup. Agric. "Luiz de Queiroz" 33: 577-582. 
MACK, H.J., 1979. Effects of row spacings, fertilizers, and harvest dates on table beets. Jour. Am. Soc. Hort. Sci. 104: 717-720.

MINAMI, K., 1977. Anālise de crescimento e densidade de popu lação de Solanum melongena L. - beringela, cultivada em delineamento sistemático e convencional. Tese de Doutoramento em Solos e Nutrição de Plantas, ESALQ, Piracicaba.

MINAMI, K.; DEMETRIO, C.G.B., 1978. Efeito da densidade de po pulação sobre a produção de cenoura (Daucus carota L.) cv . Nantes. An. Esc. Sup. Agric. "Luiz de Queiroz" 35: 483490.

MOSS, D.N.; STINSON JR., H.T., 1961. Differential response of corn hybrids to shade. Crop. Sci. 1: 416-418.

NELDER, J.A., 1962. New rinds of systematic designs for spacing experiments. Biometrics 18: 283-387.

NELDER, J.A.; MOSS, N., 1956. The spacing of lettuce in heated glasshouse. Jour. Hort. Sci. 31: 177-187.

NORTH, C., 1957. Studies in morphogenesis of Brassica oleracea L. I. Growth and development of cabbage during vegetative phase. Jour. Exp. Bot. 8: 304-312.

PEARSON, 0.H., 1931. Methods for determining the solidity of cabbage heads. Hilgardia 5: 383-393.

ROBINSON, F.E.; WORKER JR., G.F., 1969. Plant density and yield of sugar beets in an arid enviroment. Agron. Jour. 61: 441-443.

SALE, P.J., 1966. The response of summer lettuce to irrigation and plant spacing. Jour. Hort. Sci. 41: 31-42.

SNEDECOR, G.W.; COCHRAN, W.G., 1967. Statistical methods, 6a. ed., Iowa State University, Ames, 539p.

VITTUM, M.T.; TAPPLEY, W.T., 1953. Spacing and fertility levels studies with determinate type tomato. Proc. Am. Soc. Hort. Sci. 61: 339-443. 
VITTUM, M.T.; TAPLEY, W.T., 1957. Spacing and fertility leve1 studies with a past-type tomato. Proc. Am. Soc. Hort. Sci. $69: 323-326$.

WILLIAMS, W.A.; LOOMIS, R.S.; LEPLEY, C.R., 1965. Vegetative growth of corn as affected by population density. I. Productivity in relation of solar radiation. Crop Sci. 5: 211-215.

YAO, A.; SHAW, R.H., 1964a. Effect of plant population and planting pattern of corn on the distribution of net radiation. Agron. Jour. 56: 165-169.

YAO, A.; SHAW, R.H., 1964b. Effect of plant population and planting pattern of corn on water use and yield. Agron. Jour. 56: 147-151.

ZIESERL, J.F.; RIVENBARK, W.L.; HASEMAN, R.H., 1963. Nitrate reductase activity, protein content yield in four maize hybrids at varying plant populations. Corp. Sci. 3:27-32.

ZINK, F.W.; AKANA, D.A., 1951. The effect of spacing on the growth of sprouting broccoli. Proc. Am. Soc. Hort. Sci. 58: $160-164$. 